\title{
DOLNOODRZAŃSKA ENKLAWA KULTURY CERAMIKI SZNUROWEJ W RAMACH CIRCUMBAŁTYCKIEGO KRĘGU KCSZ
}

\author{
THE LOWER ODRA ENCLAVE OF THE CORDED WARE \\ CULTURE OF THE CIRCUM-BALTIC CIRCLE OF THE CWC
}

(autoreferat wygłoszony w trakcie obrony pracy doktorskiej w dniu 26 lutego 2008 r.)

\begin{abstract}
WSTĘP
W niniejszej dysertacji problem ujęto w dwóch wymiarach chorologicznych - regionalnym i szerokoprzestrzennym. W ramach pierwszego $\mathrm{z}$ nich skoncentrowałam się na obszarach u ujścia Odry. Podstawowym zamierzeniem referowanego projektu było w tym względzie stworzenie podstaw systematyki taksonomiczno-chronologicznej materiałów kultury ceramiki sznurowej z dorzecza dolnej Odry oraz podsumowanie i zweryfikowanie dotychczasowych studiów dotyczących rzeczonego zagadnienia. W wymiarzezaś szerokoprzestrzennym podjęłam próbę ukazania tego regionu na tle szerszej wspólnoty komunikacyjnej - circumbałtyckiego kręgu KCSz.

Kultura ceramiki sznurowej należy do jednostek taksonomicznych stosunkowo dobrze poznanych, nie tylko w odniesieniu do okresu neolitu, ale także szerzej - całych pradziejów. Jednak na tle zaawansowanych badań w niektórych regionach Europy (np. Jutlandia, Kujawy czy Małopolska) stan wiedzy nad zjawiskami związanymi ze schyłkiem neolitu i początkiem epoki brązu u ujścia Odry należy określić jako bardzo skromny. Najbardziej jaskrawym dowodem na poparcie tej tezy jest fakt, iż podstawowa literatura na ten temat pochodzi z lat 50. i 60. XX w. (Schroeder 1951; Siuchniński 1969).

Zakres terytorialny pracy obejmuje obszar ograniczony od zachodu doliną rzeki Wkry, od wschodu doliną rzeki Parsęty. Granicę północną stanowi południowe wybrzeże Morza Bałtyckiego, a granicę południową i wschodnią stanowią obrzeża Niziny Szczecińskiej. W analizie porównawczo-syntetyzującej obszar badań poszerzony został o strefę południowobałtycką. Uwzględnione w studium ramy chronologiczne zostały wyznaczone na podstawie periodyzację kultury ceramiki sznurowej w strefie południowobałtyckiej i obejmują lata 2900-1950/1900 p.n.e.
\end{abstract}


Do prezentowanych rozważań wykorzystano dane źródłowe z 890 stanowisk, z których pochodziły materiały kultury ceramiki sznurowej. Ich zdecydowana większość jest jeszcze z badań przedwojennych (zabytki zdeponowane w Muzeum Narodowym w Szczecinie). Zostały one uzupełnione o nowe źródła, uzyskane w ramach badań AZP oraz prospekcji powierzchniowej poprzedzającej badania wykopaliskowe na trasie planowanej drogi ekspresowej S3. Spośród materiałów pochodzących z terenów dzisiejszych Niemiec uwzględniono materiały publikowane, pochodzące ze zbiorów muzeów w Berlinie, Prenzlau i Schwerinie. Ponadto zbiór danych został uzupełniony o materiały archiwalne pozyskane podczas kwerendy w Muzeum Narodowym w Szczecinie oraz archiwum R. Schroedera zdeponowanego w Christian-Albrechts Universität w Kilonii.

\section{HISTORIA I STAN BADAŃ}

Przedstawienie historii badań nad rzeczonym zagadnieniem uwzględnia dwa istniejące równolegle nurty badawcze: „zachodni” - związany z tradycją obszaru Jutlandii, Szlezwika-Holsztynu i Meklemburgii oraz „środkowo-wschodnioeuropejski” - uwzględniający dorobek badaczy litewskich, łotewskich i polskich.

Już na poziomie zarysu historycznego dostrzegalny jest brak kompleksowej analizy materiałów źródłowych oraz refleksji metodologicznej nad omawianym zjawiskiem w niektórych regionach circumbałtyckiego kręgu KCSZ. Sytuacja ta widoczna jest szczególnie na Pomorzu Zachodnim oraz południowo-wschodnim pobrzeżu Bałtyku.

$\mathrm{W}$ dotychczasowych ujęciach prezentowanych w literaturze przedmiotu nie uwzględniano materiałów rejestrowanych po obu stronach Odry (granica państwowa była jednocześnie granicą opracowania). Ponadto analizowany obszar nie był dotychczas ukazany na szerszym tle i w konsekwencji odczuwalny jest brak przekonującego potwierdzenia źródłowego hipotezy o istnieniu południowobałtyckiej wspólnoty ugrupowań kultury ceramiki sznurowej.

\section{CHARAKTERYSTYKA ŚRODOWISKA PRZYRODNICZEGO I KULTUROWEGO}

W literaturze archeologicznej brakuje dotychczas kompleksowego omówienia problematyki środowiska przyrodniczego i kulturowego obszarów nad dolną Odrą, dotyczącego schyłkowego neolitu i wczesnej epoki brązu. W powyższej dysertacji zagadnienie to zostało podjęte. Dotychczas w polskiej literaturze szeroka analiza środowiska przyrodniczego analizowanego obszaru została zaprezentowana w publikacji dotyczącej etapu neolityzacji (Jankowska 1990).

W nawiązaniu do doświadczeń szkoły kujawskiej rozważyłam kwestię naturalnych i kulturowych czynników regionotwórczych. Rezultatem była próba odpowiedzi na pytanie: czy region u ujścia Odry możemy postrzegać jako obszar geograficzny, którego 
cechy naturalne stały się podstawą ukształtowania się w toku procesów pradziejowych przemian kulturowych, specyficznej wspólnoty regionalnej.

Stan rozpoznania źródeł dolnoodrzańskich pozwolił jedynie na wstępne uwagi odnośnie do wspomnianych kwestii. Na wczesny początek procesów regionotwórczych może wskazywać fakt zajmowania analizowanego obszaru przez społeczności wczesnoneolityczne (kultura ceramiki wstęgowej rytej). Przez długi czas tworzyły one enklawę oddzieloną geograficznie od innych centrów neolitycznych i otoczoną społecznościami mezolitycznymi i postmezolitycznymi. W odniesieniu do późniejszych ugrupowań neolitycznych (kultura pucharów lejkowatych, kultura amfor kulistych) odrębność ta nie jest tak wyraźna. Należy jednak zaznaczyć, iż wpływ na taką interpretację może mieć niedostateczny stan badań. Ze względu na swoje wyjątkowe położenie (skrzyżowanie szlaków północ - południe oraz zachód - wschód) obszar dolnoodrzański odgrywał rolę centrum wymiany informacji kulturowej.

Rozpatrując przypadek kultury ceramiki sznurowej, musimy stwierdzić z całą pewnością, że w odniesieniu do jej najstarszej fazy identyfikowanej z horyzontem ogólnoeuropejskim nie możemy mówić o istnieniu odrębnej grupy lokalnej. Dorzecze dolnej Odry było częścią rozległego obszaru penetrowanego przez ugrupowania „wczesnosznurowe”. W kolejnej fazie badane społeczności dolnoodrzańskie znalazły się w ramach szerszego kręgu wymiany informacji kulturowej związanej z kulturą grobów jednostkowych, obejmującego całą strefę południowo-zachodnio-bałtycką. W fazie najmłodszej czytelny jest pewien dualizm rozwoju. $Z$ jednej strony obserwujemy formowanie się stabilnego systemu kulturowego i jego ekspansję zewnętrzną. Jednocześnie nad dolną Odrę docierają z południa i zachodu impulsy identyfikowane z prologiem epoki brązu, o charakterze ewidentnie allochtonicznym.

\section{ZAŁOŻENIA SYSTEMATYKI ŹRÓDEL}

Głównym etapem realizacji celu prezentowanej dysertacji było usystematyzowanie materiałów źródłowych, i w konsekwencji budowa schematów typologicznych poszczególnych ich kategorii. W tym celu wykorzystałam istniejące już propozycje typologiczne opracowane według danych z terenu Kujaw (Kośko 1979; Czebreszuk 1996; Szmyt 1996). Każdorazowo były one adaptowane według specyfiki źródeł dolnoodrzańskich. Ponadto, w odniesieniu do kilku kategorii materiałów, zasugerowałam wykorzystanie propozycji odnoszących się wyłącznie do zespołów z Pomorza Zachodniego (Czebreszuk, Kozłowska 2007), Małopolski (Włodarczak 2006), czy też bardziej ogólnie - północnej Europy (Glob 1944; Struve 1955).

Pozyskane źródła charakteryzowały się dużym zróżnicowaniem pod względem wartości. Sytuacja ta spowodowana została przede wszystkim zastosowaniem zróżnicowanych standardów dokumentacyjnych. Ponadto duża część materiałów uległa zniszczeniu w wyniku działań wojennych. W rezultacie koniecznym zabiegiem stała się kategoryzacja ogółu źródeł i ich podział na kilka grup pod kątem wartości poznawczej. Analizie 
poddałam źródła o charakterze nieruchomym (osadowe, funeralne) oraz ruchomym, usystematyzowane według kryterium surowcowego.

Spośród źródeł nieruchomych najwięcej informacji o kulturze ceramiki sznurowej nad dolną Odrą dostarczyły obiekty sepulkralne. Dolnoodrzańskie materiały o charakterze osadowym nie stwarzają - na obecnym etapie - możliwości rozpoznania zarówno form osadnictwa, jak też cech sieci osadniczej i reguł jej funkcjonowania. Wśród źródeł ruchomych dolnoodrzańskiej grupy kultury ceramiki sznurowej wybijają się cechy związane przede wszystkim z ceramiką (makro- i mikromorfologia, zdobnictwo) oraz wytworami kamiennymi.

\section{CHRONOLOGIA}

Za pomocą analizy źródeł przedmiotowych oraz - w mniejszym stopniu - na podstawie uzyskanych dat radiowęglowych uściśliłam ramy chronologiczne omawianych zjawisk. Dokonałam ponadto podsumowania pozycji chronologicznej wszystkich ugrupowań związanych z kulturą ceramiki sznurowej w strefie południowobałtyckiej. Należy zaznaczyć, iż wciąż niewielka ilość oznaczeń radiowęglowych znacznie ograniczyła możliwość precyzyjniejszego ustalenia chronologii wydzielonych grup analizowanej kultury ceramiki sznurowej.

Periodyzację formalną oparłam w głównej mierze na analizie zdobnictwa i morfologii ceramiki naczyniowej. Na bazie sformułowanych założeń wyjściowych, w budowie schematu periodyzacyjnego wykorzystałam metody analizy skupień oraz seriacji. Oparłam się w nich wyłącznie na materiałach pochodzących z pewnych zespołów sepulkralnych, co do których miałam kompletne dane. Ogół zgromadzonych informacji dał podstawę do wydzielenia 3 głównych taksonów (KCSz 1, KCSz 2, KCSz 3) w ramach dolnoodrzańskiej grupy kultury ceramiki sznurowej. Grupa KCSZ 3 została dodatkowo podzielona na dwie odrębne jednostki (KCSz 3a i KCSz 3b).

$\mathrm{Z}$ perspektywy dolnoodrzańskiej etap KCSz 1 charakteryzują cechy z zakresu makromorfologii i zdobnictwa. W ramach makromorfologii są to puchary i amfory w typie A oraz smukłe puchary o łagodnie esowatym profilu. W zakresie zdobnictwa są to linie ryte oraz odciski sznura w układach jednoelementowych zwielokrotnionych, ograniczone u dołu rzędem nacięć; odciski palcowe tworzące falistą listwę plastyczną (naczynia w typie WLT) oraz ornament łączący motyw plastycznej listwy i wątek linii rytych wraz z odciskanymi punktami i nacinanymi słupkami.

Cechy reprezentatywne dla KCSz 2 wiążą się z morfologią i zdobnictwem naczyń oraz wytworami kamiennymi. Nadal obecne są puchary o esowatym profilu oraz okazy o lejkowatej szyjce. Pojawiają się amfory, garnki oraz misy. Nowością w zakresie zdobnictwa jest motyw tzw. rybiej ości i proste linie wykonane w technice rycia. Nadal obecne są wątki odcisków sznura w układach jednoelementowych zwielokrotnionych. Pojawiają się topory fasetowane typu środkowoniemieckiego oraz topory wkrzańskie. 
Za najbardziej charakterystyczne dla grupy KCSz 3a uznano cechy z zakresu makromorfologii, mikromorfologii oraz zdobnictwa. Nadal obecne są puchary o esowatym profilu, amfory i garnki. Pojawiły się kubki, naczynia wazowate i pojedyncze egzemplarze pucharów doniczkowatych. W zakresie mikromorfologii zarejestrowano ucha i czopy. W zdobnictwie pojawiły się skomplikowane motywy wykonane w technice odcisków sznura (motyw krokwiasty, tzw. wypełnione trójkąty, zdobnictwo strefowe); nadal występował motyw odcisków sznura w układzie jednoelementowym zwielokrotnionym.

Grupę KCSz 3b konstytuują cechy z zakresu makromorfologii, mikromorfologii oraz zdobnictwa. Formy morfologiczne z nią identyfikowane to: puchary o esowatym profilu, wazy, amfory i misy. Nadal występowały czopy i ucha. Nowością były skomplikowane wątki ryte, zdobnictwo strefowe, strefowo-metopowego oraz radełkowe; nadal istniał motyw tzw. wypełnionych trójkątów.

Niewątpliwym osiągnięciem przeprowadzonych studiów było pozyskanie nowych serii oznaczeń radiowęglowych dla terenu Pomorza Zachodniego, Wielkopolski i ziemi lubuskiej. W ich świetle ramy czasowe poszczególnych jednostek dolnoodrzańskiej kultury ceramiki sznurowej prezentują się następująco:

- grupa KCSz1 - 2800-2500/2400 p.n.e.

- grupa KCSz2 - 2650-2300 p.n.e.

- grupa KCSz3a - 2400/2300-2100 p.n.e.

- grupa KCSz3b - 2300/2200-1950/1900? p.n.e.

Tym, co wyróżnia analizowany obszar, jest długie ,przeżywanie się” elementów kultury ceramiki sznurowej. Prawdopodobne jest to spowodowane faktem, iż nie mamy tu do czynienia z wykształceniem się struktur związanych z ,pucharami dzwonowatymi” i kulturą unietycką, a jedynie recepcją pewnych ich elementów przez ugrupowania kultury ceramiki sznurowej. Jednak próba wyjaśnienia tego zagadnienia wymaga nowych i pogłębionych badań taksonomiczno-chronologicznych nad początkiem epoki brązu obszaru będącego przedmiotem niniejszej pracy.

\section{ANALIZA GENETYCZNA}

W omówieniu problematyki topogenezy dolnodrzańskiej grupy kultury ceramiki sznurowej podjęłam dwa podstawowe zagadnienia: a) ewentualne miejscowe komponenty genetyczne oraz b) udział elementów egzogennych w procesie formowania się omawianej jednostki taksonomicznej. Poczynione spostrzeżenia sugerują niewielki udział tradycji wiązanych z kulturą pucharów lejkowatych i kulturą amfor kulistych, rozumianych jako potencjalny komponent genetyczny. Pojawienie się przedstawicieli kultury ceramiki sznurowej nad dolną Odrą miało charakter egzogenny i należy je wiązać z przybyciem niewielkich grup ludności z zachodu (prawdopodobnie z Meklemburgii).

Analizując pozycję dolnodrzańskiej kultury ceramiki sznurowej w sieci pokrewnych wszystkich ugrupowań ze strefy południowobałtyckiej, należy wskazać na pewne cechy 
dla nich wspólne. Są to przykładowo formy naczyń, takich jak: puchary i amfory w typie A, puchary o esowatym profilu, puchary prostościenne, garnki oraz ceramika w typie WLT. $\mathrm{Z}$ pozostałych elementów inwentarza kultury ceramiki sznurowej trzeba uwzględnić konkretne typy toporów kamiennych (typ A) oraz obecność krzemiennych siekier jako elementu wyposażenia grobowego. Ponadto należy wspomnieć także o płaskich grobach jamowych bez dodatkowych konstrukcji. Należy zaznaczyć, iż różny jest stopień powtarzalności tych elementów w poszczególnych regionach oraz ich pozycja chronologiczna.

Analiza powiązań dolnoodrzańskiej grupy kultury ceramiki sznurowej z innymi ugrupowaniami w poszczególnych regionach strefy południowobałtyckiej wykazuje najwięcej cech wspólnych z rejonem Meklemburgii oraz Wielkopolski i Kujaw. Kontakty ugrupowań kultury ceramiki sznurowej znad dolnej Odry ze strefą południowo-wschodniobałtycką, w chwili obecnej rysują się jako mające ograniczoną skalę.

\section{WARIANT DOLNOODRZAŃSKI JAKO ELEMENT WSPÓLNOTY KOMUNIKACYJNEJ CIRCUMBAŁTYCKIEGO KRĘGU KCSZ}

W podsumowaniu podjęłam próbę zarysowania podstawowych zjawisk związanych z genezą i rozwojem kultury ceramiki sznurowej na analizowanym obszarze. Zwróciłam szczególną uwagę na złożony charakter relacji pomiędzy kulturą pucharów lejkowatych i kulturą amfor kulistych a kulturą ceramiki sznurowej. Udział komponentów kultury pucharów lejkowatych i kultury amfor kulistych dokumentują różnorodne zestawy źródeł. Zgromadzone informacje sugerują złożoność chronologiczną tego procesu. W fazie najstarszej mamy do czynienia z adaptacją pojedynczych elementów wiązanych generalnie z wytworami ceramicznymi. Etap drugi (KCSz 2) charakteryzuje się szerszą adaptacją cech kultury pucharów lejkowatych i kultury amfor kulistych w środowisku kultury ceramiki sznurowej. W jego trakcie możemy mówić o pewnego rodzaju otwarciu się na tradycje lokalne i ożywieniu wzajemnych relacji. Fazę KCSz 3 wyróżniają słabnące przejawy tradycji neolitycznych, co spowodowane było niewątpliwie stopniowym umacnianiem się własnych struktur, przy jednoczesnej adaptacji pierwszych wzorców protobrązowych.

Należy zaakcentować dominującą rolę więzi równoleżnikowych w fazie KCSz 1 i $\mathrm{KCSz} 2$. W początkowych etapach rozwoju społeczności dolnoodrzańskie odgrywały niewątpliwie niebagatelną rolę w sferze dystrybucji wzorców kulturowych na osi zachód - wschód. W okresie późniejszym obserwowana jest wyraźna zmiana. Istniejąca wciąż recepcja elementów zachodnich (wiązana z młodszą fazą kultury grobów jednostkowych i pucharami dzwonowatymi) ulega osłabieniu na rzecz kontaktów z południem (kultura protounietycka).

Najbardziej prawdopodobna jest hipoteza polilinearyzmu nurtów rozwoju na etapie wiązanym z KCSz 3. Polegał on na stabilizacji kulturowej i wielokierunkowej ekspansji przestrzennej ugrupowań kultury ceramiki sznurowej znad dolnej Odry, przy jednoczesnej szerokiej adaptacji cech protobrązowych. Na podstawie przeprowadzonych analiz 
udało się wzmacnić tezę o długotrwałej egzystencji badanych społeczności na analizowanym terenie. Przez długi czas ten względnie jednolity system kulturowy nie wykazywał żadnych symptomów dezintegracji. Ugrupowania dolnoodrzańskiej KCSZ przetrwały i rozwijały się w trakcie wczesnej epoki brązu.

\section{ZAKOŃCZENIE}

Ogół przeprowadzonych w dysertacji rozważań umożliwił sformułowanie nowej taksonomii i chronologii kultury ceramiki sznurowej nad dolną Odrą. Ukazał także skomplikowany charakter i dynamikę procesów zachodzących w III i na początku II tysiąclecia p.n.e. na tym terenie. Lokalne społeczności związane z kulturą ceramiki sznurowej funkcjonowały w strukturze ponadregionalnych, równoleżnikowych i południkowych powiązań. Wspomniana dynamika związana była w dużym stopniu z selektywną adaptacją obcych wzorców kulturowych. Przegląd powiązań ugrupowań wiązanych z kulturą ceramiki sznurowej nad południowym Bałtykiem, rozpatrywany na poziomie źródeł przedmiotowych, potwierdził stawianą w literaturze hipotezę o zasadniczym podziale tej strefy na część zachodnią i wschodnią.

Brak systematycznych badań w analizowanym regionie oraz charakter zaproponowanego ujęcia uniemożliwiły poruszenie wielu istotnych zagadnień bądź też pozwolił jedynie na wstępne ich zasygnalizowanie. Rozwinięcia w przyszłości będą z pewnością wymagać kwestie chronologii. Konkretyzacja i uściślenie ram czasowych omawianych zjawisk wymaga znacznego zwiększenia puli oznaczeń radiowęglowych. Uwaga ta odnosi się nie tylko do dorzecza dolnej Odry, ale też chociażby Szlezwika-Holsztynu czy Wielkopolski. Poszerzenia wymagają także kwestie dotyczące innych ugrupowań neolitycznych i wczesnobrązowych na analizowanym terenie oraz ich wzajemnych relacji. Brak wystarczającej podbudowy źródłowej uniemożliwił poruszenie zagadnienia dezintegracji struktur związanych z kulturą ceramiki sznurowej oraz mechanizmów i czynników generujących ten proces.

Praca niniejsza jest zaledwie początkiem studiów nad problematyką neolitu i wczesnej epoki brązu nad dolną Odrą. Niemniej jednak wskazuje kierunek przyszłych studiów dotyczących tej problematyki, uwzględniających niebagatelną rolę rzeki Odry jako elementu transmitującego wzorce i idee kulturowe.

\section{THE LOWER ODRA ENCLAVE OF THE CORDED WARE CULTURE OF THE CIRCUM-BALTIC CIRCLE OF THE CWC}

\section{Summary}

The present project has taken two spatial dimensions: regional and pan-regional. As far the regional dimension is concerned, I focused on the region of the lower Oder river. The main objective of this project was to create the fundamentals of taxonomic-chronological systematics of 
Corded Ware Culture materials for this region as well as summarise and verify previous achievements of studies on the aforementioned issue. However, as regards the pan-regional dimension, I attempted at discussing this region against the background of a wider communicative community - the circum-Baltic circle of Corded Ware Culture.

Agnieszka Matuszewska

Instytut Historii i Stosunków Międzynarodowych, Uniwersytet Szczeciński

ul. Krakowska 71-79, 71-017 Szczecin, Poland 